BACKGROUND: Nitric oxide (NO) production is increased in inflammatory bowel disease (IBD), and measurement of NO metabolites may be useful for monitoring disease activity.

Aims and objectives: To characterise urinary nitrite levels, a stable metabolite of NO, in IBD and to evaluate its potential as a marker of disease activity. Metbods: Twelve-hour urinary nitrites were measured by the microplate assay method in 46 patients with IBD (active; $n=32$ ). Urinary samples from 16 healthy individuals served as controls.

Results: Increased levels of urinary nitrites were found in patients with active IBD compared with those with inactive IBD. Twenty-eight out of 32 patients $(87.5 \%)$ with active IBD had detectable levels of nitrite in their urine as compared with $2 / 14$ (14.3\%) patients with inactive IBD. None of the 16 healthy controls had detectable urinary nitrite. Twelve-hour urinary nitrite in active compared with inactive IBD: $5 \overline{\mathbf{I}} 0.7$ versus $0.1 \overline{\mathbf{I}} \mathbf{0 . 0 4} \mu \mathrm{mol}(P<\mathbf{0 . 0 5})$. There was good correlation between urinary nitrite and some markers of disease activity in IBD such as C-reactive protein and microalbuminuria but not with erythrocyte sedimentation rate.

Conclusions: Increased levels of nitrite were detected in urine of patients with active IBD, consistent with increased NO synthesis. This simple assay may be exploited as a potential marker of disease activity in IBD.

Key words: Urinary nitrites, Nitric oxide, Inflammatory bowel disease

\section{Increased urinary nitrite, a marker of nitric oxide, in active inflammatory bowel disease}

\author{
Michael G. Goggins, Syed A. Shah, Jason Goh, \\ Anil Cherukuri, Donal G. Weir, Dermot Kelleher and \\ Nasir Mahmud ${ }^{\text {A }}$
}

Department of Clinical Medicine, Trinity College, Trinity Centre for Health Sciences, St. James Hospital, Dublin 8, Ireland

\author{
${ }^{\mathrm{CA}}$ Corresponding Author \\ Tel: +35316082100 \\ Fax: +35314542043 \\ E-mail: nmahmud@tcd.ie
}

\section{Introduction}

Nitric oxide (NO) is increasingly recognised to play a pivotal role in numerous physiological and pathophysiological processes since it was initially characterised as an endothelium-derived relaxing factor. ${ }^{1-3} \mathrm{NO}$ is formed from the conversion of $\mathrm{L}$-arginine to citrulline via nitric oxide synthase (NOS), ${ }^{4}$ which exists in several isoforms and can be found in numerous cell types including endothelial cells, neutrophils, macrophages, hepatocytes, enterocytes, neurons, and vascular smooth muscle. ${ }^{5-8}$ In the gastrointestinal tract, NO participates in neurotransmission, ${ }^{9}$ smooth muscle relaxation, ${ }^{10}$ intestinal secretion, maintenance of intestinal blood flow and as an inflammatory mediator. ${ }^{10,11}$ Recent studies have demonstrated that NO production is increased in inflammatory bowel disease (IBD) ${ }^{12-17}$ Factors influencing a physiological or pathological outcome subsequent to increased NO production include the redox state of the molecule, its local concentration and its potential to form toxic intermediary metabolites. ${ }^{2,7}$
NO is ultimately metabolised to stable end products that include nitrite and nitrate. ${ }^{2,18,19}$ The relative amount of nitrite and nitrate produced by NO breakdown depends on the $\mathrm{pH}$ and redox state of the environment in which it is produced. ${ }^{18,19}$ In experimental animals, urinary nitrite reflects systemic rather than renal production of NO. Nitrite has been used as a marker of NO production in culture fluids, plasma, synovial fluid and urine. ${ }^{20,21}$ It has been found that plasma nitrite is increased in patients with rheumatoid arthritis compared with healthy controls and also that levels were significantly higher in the synovial fluid than in plasma. ${ }^{21}$ Interleukin II immunotherapy causes a significant elevation in plasma nitrate levels. ${ }^{22}$ Plasma nitrite levels have also been detected in other conditions such as sepsis, ${ }^{23}$ cirrhosis $^{24}$ and fulminant hepatic failure,$^{25}$ and in the postoperative period. $^{26}$

Estimation of nitrite is a useful marker of NO synthesis and may potentially be used as an indicator of disease activity in chronic inflammatory conditions such as IBD. 


\section{Methods}

\section{Patients}

Forty-six patients were enrolled for the study. Thirtytwo (69\%) patients had active IBD at the time of study. Active IBD was defined as a Harvey-Bradshaw index $(\mathrm{HBI})^{27}>3$. Twenty-five patients had Crohn's disease (CD) and 21 patients had ulcerative colitis (UC) (pancolitis; $n=6$ ). Sixteen healthy laboratory personnel served as controls. Thirty patients were receiving oral aminosalicyclates, four patients were receiving corticosteroids and 15 patients were receiving no medication at the time of urinary sampling.

\section{Urinary nitrite estimation}

Timed 12-h urine collections were performed on all patients. A microplate assay method was used to quantify urinary nitrite. An equal volume of the Griess reagent $(0.1 \%$ sulphonide, $0.1 \%$ naphthylethylenediamine dihydrochloride, $2.5 \%$ phosphuric acid) was added to urine samples or to urine nitrite standards and incubated at room temperature for $10 \mathrm{~min}$. Absorbance was performed by spectrophotometry at $540 \mathrm{~nm}^{27}$ The limit of detection of nitrite was 1 micromole per litre $(1 \mu \mathrm{mol} / \mathrm{l})$. Urinary nitrite concentration was determined and 12-h urinary nitrite production calculated.

\section{Assessment of disease activity}

Disease activity was measured using the HBI, erythrocyte sedimentation rate (ESR) and C-reactive protein (CRP) and microalbuminuria. CRP and microalbuminuria were measured by the immunoturbometric method (Behring, Germany) as previously described. ${ }^{28}$

\section{Statistics}

The Wilcoxon rank sum test was used for nonparametric data and the non-paired Student $t$-test for parametric data. Correlations were determined using simple regression analysis. Statistics were performed using Statworks software.

\section{Ethics}

The study was approved by the Joint Ethics Committee of St. James's Hospital and Adelaid and Meath Hospital incorporating National Children's hospital Tallaght. Written informed consent was obtained from all study subjects prior to phlebotomy and urinary sampling.

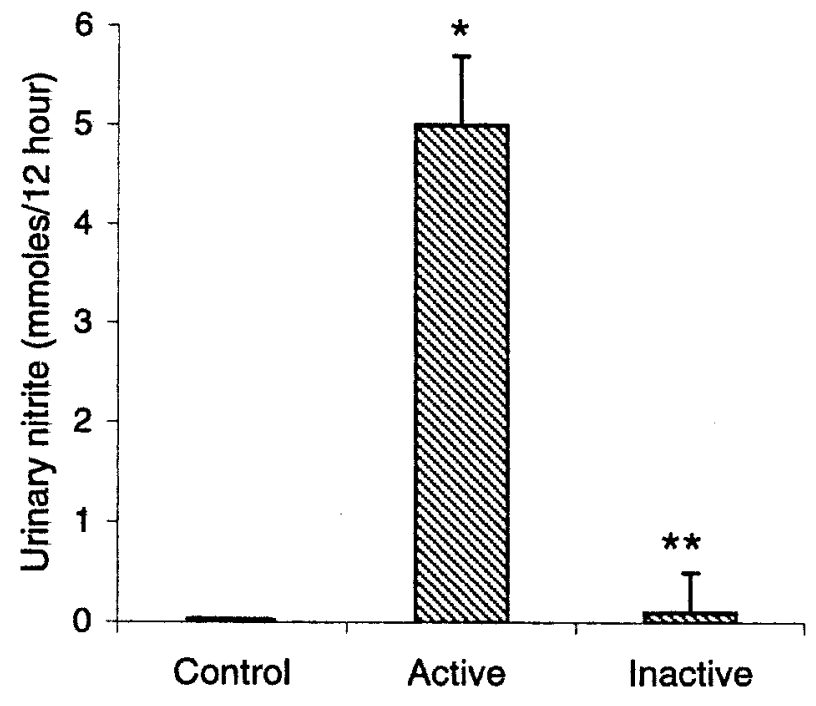

FIG. 1. Timed 12-h urinary nitrite was assayed in patients with active and inactive inflammatory bowel disease (as defined by the Harvey-Bradshaw index $(n=32$ and $n=14$, respectively)). ${ }^{*} P<0.05$ versus control, ${ }^{* *} P<0.05$ versus active disease.

\section{Results}

\section{Urinary nitrite in IBD}

Twenty of $32(87.5 \%)$ patients with active IBD had detectable urinary nitrite. In contrast, only two of 14 (14.2\%) patients with inactive IBD had low levels of urinary nitrite. None of the 16 healthy controls had any nitrite in their urine. Twelve-hour urinary nitrite in active compared with inactive IBD was $5 \pm$ $0.7 \mu \mathrm{mol}$ versus $0.1 \pm 0.04 \mu \mathrm{mol} / 12 \mathrm{~h}(P<0.05)$ (Fig. 1). Urinary nitrite in controls was $0 \pm 0 \mu \mathrm{mol}(P<$ $0.05)$. There was no difference in urinary nitrite level between patients with $\mathrm{CD}$ and UC: $4.1 \pm 0.8 \mu \mathrm{mol} /$ $12 \mathrm{~h}$ versus $2.2 \pm 0.44 \mu \mathrm{mol} / 12 \mathrm{~h}(P=$ not significant (NS)). The urinary nitrite concentration was also significantly higher in patients with active IBD compared with inactive IBD $(25.5 \pm 6.8 \mu \mathrm{mol} / 1$ versus $0.15 \pm 0.05 \mu \mathrm{mol} / 1$, respectively; $P<0.05)$.

Comparing urinary nitrite in active $\mathrm{CD}$ and inactive $\mathrm{CD}$, urinary nitrite was $10 \pm 2.8 \mu \mathrm{mol} / 12 \mathrm{~h}$ versus $0 \pm$ $0 \mu \mathrm{mol} / 12 \mathrm{~h}(P<0.05)$ (Fig. 2$)$. In patients with active UC compared with inactive UC, urinary nitrite was 16 $\pm 3.7 \mu \mathrm{mol} / 12 \mathrm{~h}$ versus $0 \pm 0 \mu \mathrm{mol} / 12 \mathrm{~h}$ (Fig. 2). There was no difference in urinary nitrite levels between patients with active disease on treatment compared with patients on no treatment $(9.4 \pm 6.8 \mu \mathrm{mol} / 12 \mathrm{~h}$ versus $8.8 \pm 1.29 \mu \mathrm{mol} / 12 \mathrm{~h} ; P=\mathrm{NS}$ ) (Fig. 3).

\section{Relationship between urinary nitrite and disease activity markers}

Patients with active IBD had significantly higher levels of microalbuminuria than those with inactive disease. There was a strong correlation between microalbuminuria and urinary nitrite in $\mathrm{CD}(r=0.88, P<$ 


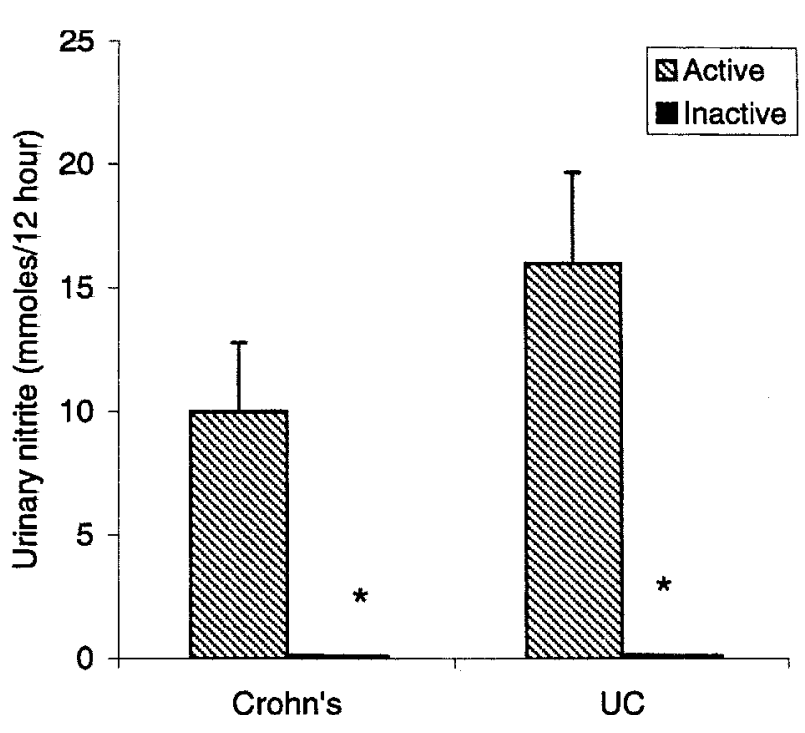

FIG. 2. Timed 12-h urinary nitrite stratified according to disease activity and inflammatory bowel disease (IBD) subtype (Crohn's disease and ulcerative colitis (UC)). ${ }^{*} P<$ 0.05 versus active disease.

0.01) (Table 1). In contrast, there was no correlation between microalbuminuria and urinary nitrite in UC ( $r<0.1, P=$ NS) (Table 1). There was a strong correlation between urinary nitrite in CD and serum CRP level $(r=0.66, P<0.05)$. The correlation between urinary nitrite and serum CRP in UC did not reach statistical significance $(r=0.47, P=\mathrm{NS})$. The levels of CRP were higher in urinary nitrite-positive

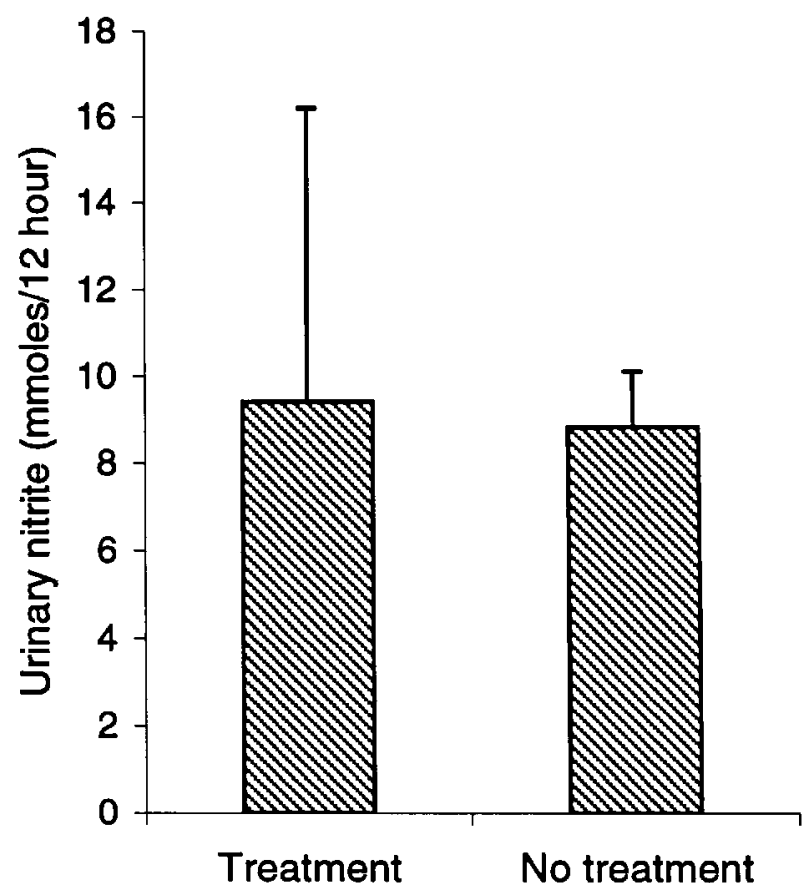

FIG. 3. The effect of concurrent anti-inflammatory medication on 12-h urinary nitrite was assessed among patients with active inflammatory bowel disease $(n=32)$. No statistical difference was detected between the groups.
Table 1. Correlation coefficient $(r)$ between urinary nitrite and markers of disease activity (microalbuminuria and serum C-reactive protein (CRP))

\begin{tabular}{lcc}
\hline & Crohn's disease & Ulcerative colitis \\
\hline Microalbuminuria & $0.88^{*}$ & $<0.1$ \\
Serum CRP & $0.66^{* *}$ & 0.47 \\
\hline$* P<0.01 * * P<0.05$ &
\end{tabular}

${ }^{*} P<0.01,{ }^{*} P<0.05$.

patients than in nitrite-negative patients $(32.5 \pm$ $4.9 \mu \mathrm{mol} / \mathrm{l}$ versus $5.7 \pm 1.9 \mu \mathrm{mol} / \mathrm{l} ; P<0.05)$.

There was no significant correlation between levels of urinary nitrite and HBI. ESR was higher in the active IBD group compared with the inactive group $(27.6 \pm 20$ versus $10.7 \pm 3 ; P=0.05)$. There was no difference in the ESR in the urinary nitrite-positive patients compared with the urinary nitrite-negative patients (22.8 $\pm 15 \mathrm{~mm}$ versus $23 \pm 2.5 \mathrm{~mm}$ in the first hour; $P=$ NS).

\section{Discussion}

This study demonstrates that urinary nitrite was detectable in IBD and higher levels were observed during active disease. These data support previous findings of increased NO generation in active IBD. ${ }^{18,19}$ Previous investigations have demonstrated increased plasma nitrite/nitrate levels and increased mucosal citrulline production in active IBD. Elevated urinary nitrate and nitrite were not exclusive to IBD but have been observed in other inflammatory conditions of the bowel including infectious and radiation enterocolitis. ${ }^{18}$ In our study, urinary nitrite levels appeared to correlate with laboratory indices of disease activity in Crohn's disease but not in ulcerative colitis. Evidence for increased NO production has also been demonstrated in experimental models of IBD. Peroxynitrite-induced colitis in experimental models can be ameliorated by inducible NOS (iNOS) inhibitors. ${ }^{71,13,29,30}$ It has also been shown that NOS activity was increased in the colonic mucosa of patients with IBD, ${ }^{15,17}$ and that increased nitrite levels were detected in rectal diasylate of patients with active IBD, especially in active UC. ${ }^{14,31}$ But, in the case of $\mathrm{CD}$, there is conflicting evidence: low colonic NOS activity in one study, ${ }^{17}$ and higher NOS activity in the others. $^{13,15,32,33}$

The origin of urinary nitrite in IBD is unknown. Our observation of similar levels of urinary nitrite in UC and CD patients despite reported differences in colonic levels of NOS may suggest that systemic production of NO may be a major source of urinary nitrite in IBD. A potential source of NO production is the peripheral blood macrophages, following iNOS induction in response to pro-inflammatory cytokines and endotoxins. Furthermore, bacterial translocation 
may be another source of urinary nitrite. Endotoxaemia is a recognised feature of IBD, and bacterial translocation has been associated with increased urinary nitrate production in animal studies. ${ }^{34}$ Another source of NO may be the intestinal epithelial cells, which have been shown to possess NO activity in animal studies. ${ }^{35}$

We have shown that the levels of urinary nitrite correlate with microalbuminuria and CRP in CD. It is possible that renal production of NO following proinflammatory stimuli may contribute to the urinary nitrite detected in these subjects. A renal source of urinary nitrite has also been recently suggested in patients with urinary tract infection. ${ }^{36}$ Previous studies in experimental models have demonstrated that, although inflamed glomeruli are capable of producing nitrite, urinary nitrite in experimental glomerulonephritis reflects systemic NO formation as a result of immune activation rather than glomerular production of NO. ${ }^{37,38}$ This suggests that, although conversion of nitrite to nitrate is rapid in vivo, at least some of the nitrite produced systemically as a result of NO production is cleared by the kidneys before it is converted to nitrate. NO may contribute to the pathogenesis of IBD through its pro-inflammatory effects (local cell injury, intestinal hyperaemia), its effects on neurotransmission, fluid secretion and its ability to induce smooth muscle relaxation.

There are limitations to the application of nitrite measurement as a marker of NO production and routine laboratory marker of disease activity in IBD. The additional measurement of urinary nitrate, the other stable end product of NO metabolism, may provide further information regarding in vivo NO status. ${ }^{39}$ It is conceivable that dietary arginine or nitrite intake could have influenced urinary nitrite levels among this cohort. Nevertheless, urinary nitrite was not present in healthy individuals at levels within the detection limits of our assay.

In conclusion, patients with active IBD have elevated levels of urinary nitrite, a stable end product of NO. Measurement of urinary nitrite may serve as a useful marker for monitoring disease activity in IBD.

\section{References}

1. Ignarro LJ, Buga GM, Wood KS, Byrns RE, Chaudhuri G. Endotheliumderived relaxing factor produced and released from artery and vein is nitric oxide. Proc Natl Acad Sci USA 1987; 84: 9265-9269.

2. Moncada S, Higgs A. Mechanisms of disease: the L-arginine-nitric oxide pathway. N Engl J Med 1993; 329: 1977-2048.

3. Stamler JS, Singel DJ, Loscalzo J. Biochemistry of nitric oxide and its redox-activated forms. Science 1992; 258: 1898-1902.

4. Moncada S, Palmer RMJ, Higgs EA. Biosynthesis of nitric oxide from 1-arginine: a pathway for the regulation of cell function and communication. Biochem Pharmacol 1989; 38: 1709-1715.

5. McCall TB, Boughton-Smith NK, Palmer RMJ, Whittle BJR, Moncada S Synthesis of nitric oxide from L-arginine by neutrophils: release and interaction with superoxide anion. Biochem J 1989; 261: 293-296.

6. Palmer RMJ. The discovery of nitric oxide in the vessel wall: a unifying concept in the pathogenesis of sepsis. Ann Surg 1993; 128: 396-401.

7. Kubes P, McCafferty DM. nitric oxide and intestinal inflammation. Am J Med 2000; 109: 150-158.
8. Green JT, Richardson C, Marshall RW, Rhodes J, Mckirdy C, Thomas GAO, Williams GT. Nitric oxide mediates a therapeutic effect of nicotine in ulcerative colitis. Aliment Pharmacol Therap 2000; 11: 1429-1434.

9. Stark ME, Szurswewski JH. Role of nitric oxide in gastrointestinal and hepatic function and disease. Gastroenterology 1992; 103: 1928-1949.

10. Miller MJS, Sadowska-Krowicka H, Chotinaruemol S, Kakkis JL, Clark DA Amelioration of chronic ileitis by nitric oxide synthase inhibition. $J$ Pharm Exp Ther 1993; 264: 11-16.

11. Miller MJ, Zhang XJ, Sadowska-Krowicka H, Chotinaruemol S, McIntyre JA, Clark DA, Bustamante SA. Nitric oxide release in response to gut injury. Scand J Gastroenterol 1993; 28: 149-154.

12. Armstrong AM, Campbell GR, Gannon C, Kirk SJ, Gardiner KR. Oral administration of inducible nitric oxide synthase inhibitor reduces nitric oxide synthesis but has no effect on severity of experimental colitis Scand J Gastroentrol 2000; 35: 832-838.

13. Parner A, Rask-Madsen J. The potential role of nitric oxide in chronic inflammatory bowel disease. Aliment Pharmcol Ther 1999; 2 135-144.

14. Roediger WE, Lawson MJ, Radcliffe BC. Nitrite from inflammatory cells: a cancer risk factor in ulcerative colitis. Dis Colon Rectum 1990; 33: 1034-1036.

15. Boughton-Smith NK, Evans SM, Hawkey CJ, Cole AT, Balsitis M, Whittle BJ, Moncada S. Nitric oxide synthase activity in ulcerative colitis and Crohn's disease. Lancet 1993; 342: 338-340.

16. Singer II, Kawka DW, Scott S, Weidner JR, Mumford RA, RiehlTE, Stenson WF. Expression of inducible nitric oxide synthae and nitrotyrosine in colonic epithelium in inflammatory bowel disease. Gastroenterology 1996; 111: 871-885.

17. Middleton SJ, Shorthouse M, Hunter JO. Relaxation of distal colonic circular smooth muscle by nitric oxide derived from human leucocytes. Gut 1993; 34: 814-817.

18. Reimund JM, Duclos B, Koehl C, Lehr L, Ezenfis J, Baumann R. Nitric oxide end products in patients hospitalized for diarrhoea. Eur $J$ Gastroenterol Hepatol 1999; 11: 1013-1018.

19. Sasajima K, Yoshida Y, Yamakado S, Sato J, Miyashita M, Okawa K, Matsutani T, Onda M, Kawano E. Changes in urinary nitrate and nitrite during treatment of ulcerative colitis. Digestion 1996; 57: 170-173.

20. Wennmalm $\AA$, Petersson AS. Analysis of nitrite as a marker for endothelium-derived relaxing factor in biological fluids using electron paramagnetic resonance spectroscopy. J Cardiovas Pharmacol 1991; 17 (Suppl 3): S34-S40.

21. Farrell AJ, Blake DR, Palmer RM, Moncada S. Increased concentrations of nitrite in synovial fluid and serum samples suggest increased nitric oxide synthesis in rheumatic diseases. Ann Rheum Dis 1992; 51 1219-1222.

22. Hibbs JB, Westenfelder C, Taintor R, Vavrin Z, Kablitz C, Baranowski KL, Ward JH, Menlove RL, McMurry MP, Kushner JP. Evidence for cytokineinduced nitric oxide synthesis from L-arginine in patients receiving interleukin-2 therapy. J Clin Invest 1992; 89: 867-877.

23. ShiY, Li HQ, Shen CK, Wang JH, Qin SW, Liu R, Pan J. Plasma nitric oxide levels in newborn infants with sepsis. J Pediatr 1993; 123: 435-438.

24. Guarner C, Soriano G, Tomas A, Bulbena O, Novella MT, Bolanzo J, Vilardell $\mathrm{F}$. Increased serum nitrite and nitrate levels in patients with cirrhosis: relationship to endotoxemia. Hepatology 1993; 18 1139-1143.

25. Wendon et al. Plasma nitrite in fulminant hepatic failure. Lancet 1994; 344: 611 .

26. Wendon J, Harrison PM, Heaton N, William R. Serum nitrates as markers of postoperative morbidity. Lancet 1994; 344: 410-411.

27. Harvey RF, Bradshaw JW. A simple index of Crohn's disease activity. Lancet 1980; 1: 514

28. Mahmud, N, Stinson J, O'Connell M, Mantle T, Keeling PWN, Feely J, Weir DG, Kelleher D. Microalbuminuria in patients with inflammatory bowel disease. Gut 1994; 35: 1599-1604.

29. Mckenzie SJ, Baker MS, Buffinton GD, Doe WF. Evidence of oxidantinduced injury to epithelial cells during inflammatory bowel disease. Clin J Invest 1996; 989: 136-141.

30. Miller MJ, Thomson JH, Zhang XJ, Sadowaska-Krowicka H, Kakis JL, Munshi UK, Sandoval M, Rossi JL, Eloby-Chilress S, Beckman JS. Role of inducible nitric oxide synthase expression and peroxynitrite formation in guinea pig ileitis. Gastroenterology 2000; 109: 1475-1483.

31. Roediger WE, Lawson MJ, Nance SH, Radcliffe BC. Detectable colonic nitrite levels inflammatory bowel disease - mucosal or bacterial malfunction? Digestion 1986; 35: 199-204.

32. Cavicchi M, Gibbs L, Whittle BJ. Inhibition of inducible nitric oxide synthase in human epithelial cell line DLD-1, by the inducers of haeme oxygenase, bismuth salt, haeme and nitric oxide donors. Gut 2000; 47 : 771-778

33. Binion DG, Rafiee P, Ramanujam KS, Fu S, Fisher PJ, Rivera MT, Johnson CP, Otterson MF, Telford GL, Wilson KT. Deficient inducible nitric oxide synthase in inflammatory bowel disease intestinal microvasculature endothelial cells result in increased leucocyte adhesion. Free Radic Biol Med 2000; 29: 881-888.

34. Oudenhoven IMJ, Klaasen HLBM, Larpré JA, Weerkamp AH, Van der meer R. Nitric oxide-derived urinary nitrate as a marker of intestinal bacterial translocation in rats. Gastroenterology 1994; 107: 47-54. 
35. Sartour RB. Cytokines in intestinal inflammation: pathophysiological and clinical considerations. Gastroenterology 1994; 106: 533-539.

36. Smith SD, Wheeler MA, Weiss RM. Nitric oxide synthase: an endogenous source of elevated nitrite in infected urine. Kidney Int 1994; 45: 586-591.

37. Cattell V, Cook T, Moncada S. Glomeruli synthesis nitrite in experimental nephrotoxiic nephritis. Kidney Int 1990; 38: 1056-1060.

38. Sever R, Cook T, Cattell V. Urinary excretion of nitrite and nitrate in experimental glomerulonephritis reflects systemic immune activation and not glomerular synthesis. Clin Exp Immunol 1992; 90: 326-329.

39. Guo X, Wang WP, Ko JK, Cho $\mathrm{CH}$. Involvement of neutrophils and free radicals in the potentiating effects of passive cigarette smoking in inflammatory bowel disease. Gastrenterology 1999; 117: 884-892.

Accepted 28 February 2001 


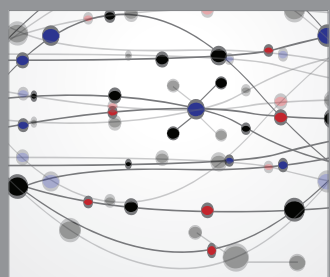

The Scientific World Journal
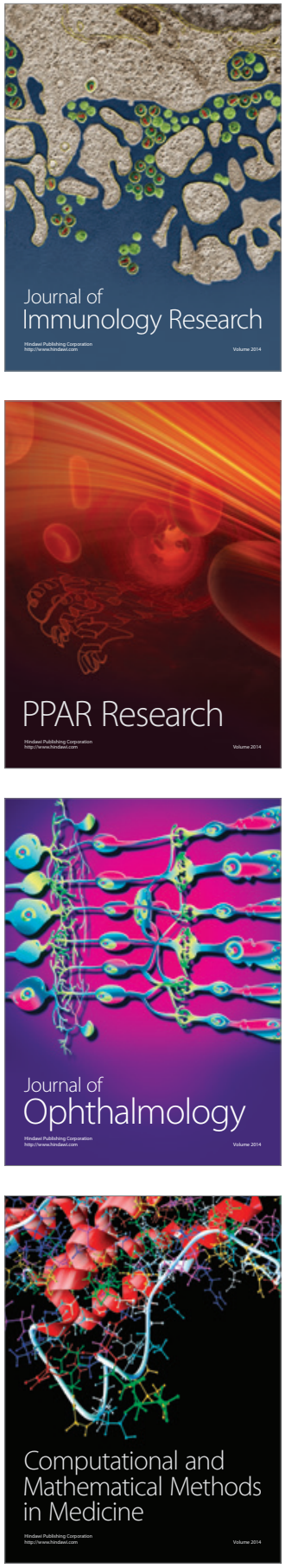

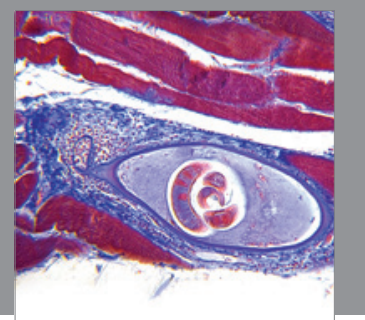

Gastroenterology

Research and Practice
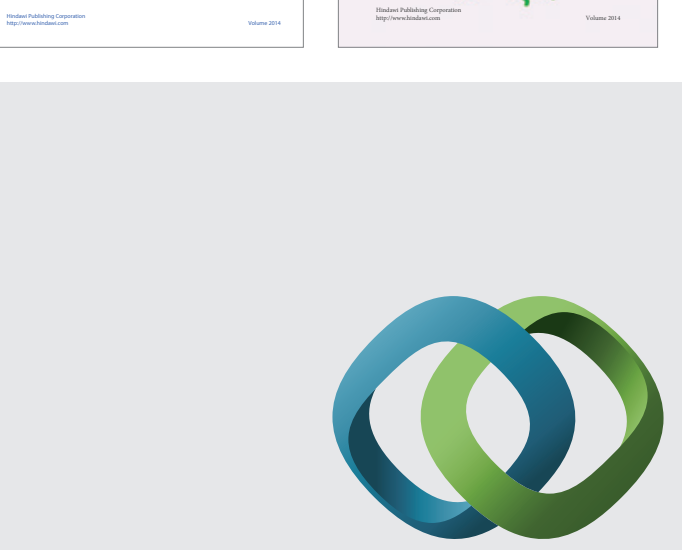

\section{Hindawi}

Submit your manuscripts at

http://www.hindawi.com
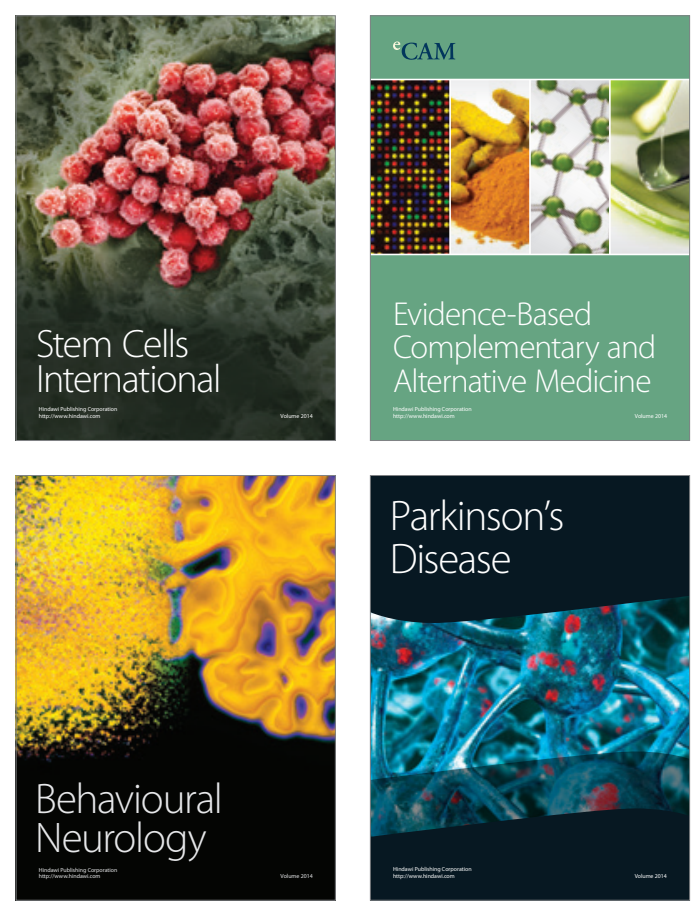

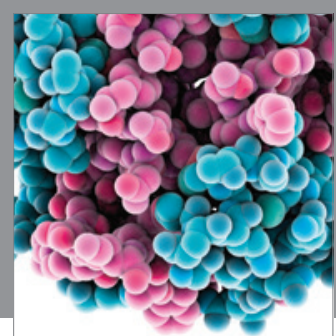

Journal of
Diabetes Research

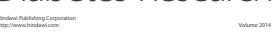

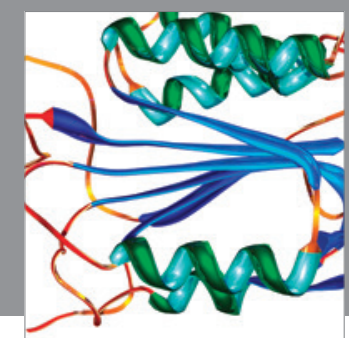

Disease Markers
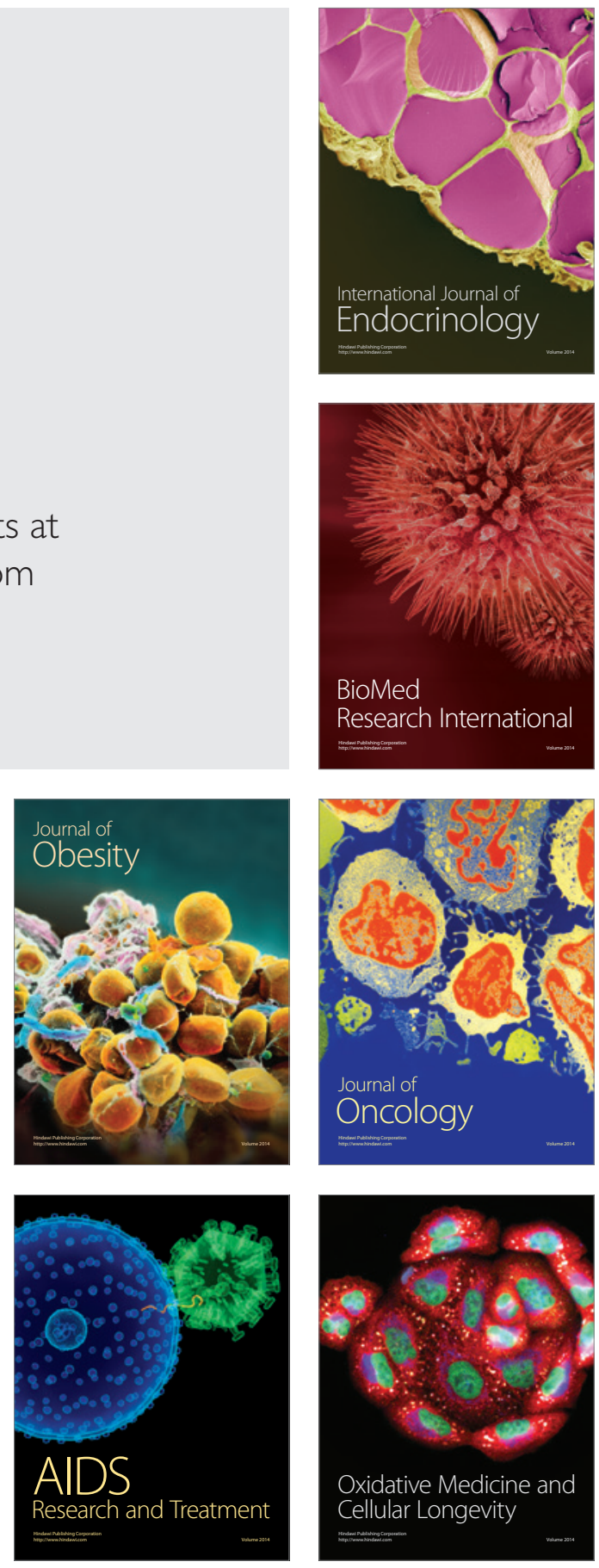